\title{
Postoperative Complication in Overweight Patients Undergoing Coronary Artery Bypass Graft Surgery
}

\author{
Mohammed Abd Elzaher Abd El Motaleb', Tamer Hikal², Mohammed Nabil Abd Al Jawad2* (1), \\ Hani Metwaly², Mohsen Fadala² \\ ${ }^{1}$ Department of Cardio-Thoracic Surgery, National Heart Institute, Cairo, Egypt \\ ${ }^{2}$ Department of Cardio-Thoracic Surgery, Ain Shams University, Cairo, Egypt \\ Email: mohammed_abdaljawad@med.asu.edu.eg, ma.abdelzaher7@yahoo.com, tammerhikal77@gmail.com, \\ *mohammed_abdaljawad@med.asu.edu.eg, hani_abd_mabood@yahoo.com,mohsenfadala@hotmail.com
}

How to cite this paper: El Motaleb, M.A.E.A., Hikal, T., Abd Al Jawad, M.N., Metwaly, H. and Fadala, M. (2019) Postoperative Complication in Overweight Patients Undergoing Coronary Artery Bypass Graft Surgery. World Journal of Cardiovascular Surgery, 9, 53-62. https://doi.org/10.4236/wjcs.2019.96007

Received: May 19, 2019

Accepted: June 25, 2019

Published: June 28, 2019

Copyright (c) 2019 by author(s) and Scientific Research Publishing Inc. This work is licensed under the Creative Commons Attribution International License (CC BY 4.0).

http://creativecommons.org/licenses/by/4.0/

\begin{abstract}
Background: Obesity has a great impact on overall mortality and morbidity in cardiac surgery. The magnitude of obesity is defined by means of body mass index (BMI). At this study we aim to correlate between grade of BMI and postoperative complications in patients undergoing coronary revascularization. Methods: A prospective observational study was conducted in Ain Shams University hospitals and the National Heart Institute of Egypt. 98 patients with multi-vessel CAD and candidate for CABG were included in the study and divided into two groups Group I: 53 patients with BMI over 30. Group II: 45 patients with a BMI under 30 . The primary endpoint was wound infection and mediastinitis. Secondary endpoints included mortality, prolonged ICU and hospital stay, stroke, renal and hepatic impairment. Results: As regard primary ending point, eight patients of Group I had their wounds infected which is significantly higher than the other group (p-value 0.034). The total ward stay in days was significantly higher in Group I (p-value 0.027). Conclusion: BMI more than 30 is associated with increased rates of wound complications either superficial or deep wound infections. Robust measures should be taken to prevent such grave complications.
\end{abstract}

\section{Keywords \\ Obesity, Coronary Artery Bypass, Outcomes}

\section{Introduction}

Obesity is without doubt a heavy burden both for patients and healthcare sys- 
tems alike; a burden which is greatly increased in cardiac surgery patients, especially those in need of coronary revascularization.

Body Mass Index (BMI) is the scale by which populations are classified according to their obesity. Patients with $\mathrm{BMI} \geq 30 \mathrm{Kg} / \mathrm{m}^{2}$ were classified as obese and those with $\mathrm{BMI}<30 \mathrm{Kg} / \mathrm{m}^{2}$ considered as non-obese [1] [2]. Controversies still exist between authors regarding whether a high BMI is associated with more complications or not in cardiac surgery. Among those who propose a significant increase of mortality and morbidity in obese patients is Engelman and colleagues [3]. While Reeves and his team showed some increase in rates of complications but neither reaching a statistical significance [4].

Wound complications either superficial or deep infections were among the first discussed in obese patients. This is also true for ICU stay, and ventilation hours which subsequently increase the total hospital stay for those patients. Simopoulos in his published manuscript, proved an association between high BMI and wound infection rates, which significantly affected the mortality in his series [5].

At this study, we aim to correlate between grade of BMI and postoperative complications in patients undergoing coronary revascularization.

\section{Patients and Methods}

After approval of Ain Shams University and National Heart Institute Ethical committee for the study proposal between October 2017 and June 2018, prospective observational study was conducted in Ain Shams University hospitals and National Heart Institute of Egypt. Ninety-eight patients with multi-vessel coronary artery disease and candidate for CABG were included in the study and divided into two groups Group I: 53 patients with BMI over 30. Group II: 45 patients with a BMI under 30 .

\subsection{Inclusion Criteria}

All Patients presented with ischemic heart disease scheduled for elective CABG.

\subsection{Exclusion Criteria}

1) HBA1c of more than 7.5

2) Patients with ischemic mitral valve disease

3) Emergency CABG

4) Redo CABG

5) Significant stenosis of the carotid artery with $C A B G$ and preoperative comorbidities (hepatic, renal, and pulmonary)

Patients underwent uniform anesthetic and surgical procedures. Revascularization was done using conventional pedicled LIMA harvesting and saphenous vein grafts as needed. All procedures were done by means of on-pump CABG, moderate hypothermia $\left(28^{\circ} \mathrm{C}-32^{\circ} \mathrm{C}\right)$, utilizing antegrade intermittent blood enriched cardioplegia. Strict hypoglycemic status was achieved and maintained 
below $200 \mathrm{mg} / \mathrm{dL}$.

Collected data were cross-clamp and total bypass times. The need for intra-aortic balloon pump and inotropic support were also recorded.

The primary endpoint was wound infection and mediastinitis. Secondary endpoints included mortality, prolonged ICU and hospital stay, stroke, renal and hepatic impairment.

\subsection{Statistical Analysis}

Data were expressed as mean \pm standard deviation (SD) percentages (\%) as indicated. For categorical variables, we used Chi-square test and Fisher. For numerical variables, we used student's t-test. $\mathrm{P}$ value $\leq 0.05$ was considered a statistically significant result.

\subsection{Sample Size}

Sample size calculation was made based on the work of Ridderstolpe and colleagues showing a prevalence of all sternal wound infections of $10.6 \%$ of a study population of 2108 patients. Using Medcalc ${ }^{\circledR}$ software with a type I error of 0.05 , type II error of 0.1 ; the minimum sample size per group was 38 patients per group [6].

\section{Results}

There is a statistically insignificant difference between group I and group II as regard age and sex; however, the prevalence of CABG in male patients (62) is more than in female patients (36). The mean age in both groups was about the same $(53.45 \pm 6.6,54.89 \pm 6.13)$ as shown in Table 1. Group I had a higher prevalence of hypertension and DM rather than group II (58.5\% versus $51.1 \%$ ) (56.6\% versus $46.7 \%)$ respectively with no significant difference, as shown in Table 2.

Table 3 shows preoperative echocardiography characteristics, there is a statistically insignificant difference between group I (BMI > 30) and group II $(\mathrm{BMI}<30)$

Table 1. Patients' demographics.

\begin{tabular}{|c|c|c|c|c|c|c|}
\hline \multirow{3}{*}{ Variables } & \multicolumn{4}{|c|}{ Patient Group } & \multirow{3}{*}{$\begin{array}{l}\text { Independent } \\
\text { sample t-test }\end{array}$} & \multirow{3}{*}{$\mathrm{P}$-value } \\
\hline & \multicolumn{2}{|c|}{$\begin{array}{c}\text { Group I } \\
\text { BM I > } 30\end{array}$} & \multicolumn{2}{|c|}{$\begin{array}{l}\text { Group II } \\
\text { BMI }<30\end{array}$} & & \\
\hline & Mean & $\pm \mathrm{SD}$ & Mean & $\pm \mathrm{SD}$ & & \\
\hline Age (in years) & 53.45 & 6.60 & 54.89 & 6.13 & -1.109 & 0.270 \\
\hline \multirow{3}{*}{ Variables } & \multicolumn{4}{|c|}{ Patient Group } & \multirow{3}{*}{ Chi square test } & \multirow{3}{*}{ P-value } \\
\hline & \multicolumn{2}{|c|}{$\mathrm{BMI}>30$} & \multicolumn{2}{|c|}{$\mathrm{BMI}<30$} & & \\
\hline & No. & $\%$ & No. & $\%$ & & \\
\hline \multirow[b]{2}{*}{ Female } & 32 & $60.4 \%$ & 30 & $66.7 \%$ & \multirow{2}{*}{0.414} & \multirow{2}{*}{0.520} \\
\hline & 21 & $39.6 \%$ & 15 & $33.3 \%$ & & \\
\hline
\end{tabular}

Values are shown as mean $\pm \mathrm{SD}$, numbers and percentages as indicated, BMI Body Mass Index. 
Table 2. Patient cohort co-morbidities.

\begin{tabular}{|c|c|c|c|c|c|c|c|}
\hline & & \multicolumn{4}{|c|}{ Patient Group } & \multirow{3}{*}{ Chi square test } & \multirow{3}{*}{$\mathrm{P}$-value } \\
\hline \multicolumn{2}{|c|}{ Variables } & \multicolumn{2}{|c|}{$\begin{array}{c}\text { Group I } \\
\text { BMI }>30\end{array}$} & \multicolumn{2}{|c|}{$\begin{array}{l}\text { Group II } \\
\text { BMI }<30\end{array}$} & & \\
\hline & & No. & $\%$ & No. & $\%$ & & \\
\hline \multirow{2}{*}{ HTN } & No & 22 & $41.5 \%$ & 22 & $48.9 \%$ & \multirow{2}{*}{0.536} & \multirow{2}{*}{0.464} \\
\hline & Yes & 31 & $58.5 \%$ & 23 & $51.1 \%$ & & \\
\hline \multirow{2}{*}{ DM } & No & 23 & $43.4 \%$ & 24 & $53.3 \%$ & \multirow{2}{*}{0.963} & \multirow{2}{*}{0.326} \\
\hline & Yes & 30 & $56.6 \%$ & 21 & $46.7 \%$ & & \\
\hline
\end{tabular}

Values are shown as mean \pm SD, numbers and percentages as indicated, BMI Body Mass Index, HTN systemic hypertension Diabetes Mellitus.

Table 3. Preoperative echocardiography.

\begin{tabular}{|c|c|c|c|c|c|c|}
\hline \multirow{3}{*}{ Variables } & \multicolumn{4}{|c|}{ Patient Group } & \multirow{3}{*}{$\begin{array}{l}\text { Independent } \\
\text { sample t-test }\end{array}$} & \multirow{3}{*}{$\mathrm{P}$-value } \\
\hline & \multicolumn{2}{|c|}{$\mathrm{BMI}>30$} & \multicolumn{2}{|c|}{$\mathrm{BMI}<30$} & & \\
\hline & Mean & $\pm \mathrm{SD}$ & Mean & $\pm \mathrm{SD}$ & & \\
\hline End Diastolic Dimension & 5.65 & 0.63 & 5.63 & 0.68 & 0.183 & 0.855 \\
\hline End Systolic Dimension & 4.61 & 6.10 & 3.72 & 0.60 & 0.964 & 0.337 \\
\hline Ejection Fraction & 54.47 & 8.22 & 52.44 & 7.16 & 1.290 & 0.200 \\
\hline
\end{tabular}

Values are shown as mean $\pm \mathrm{SD}$, numbers and percentages as indicated, BMI Body Mass Index.

as regard Pre-operative End Systolic and Diastolic dimension and Ejection Fraction $(\mathrm{P}>0.05)$; however; group I (BMI > 30) had higher mean Pre-operative End Systolic and Diastolic dimension rather than group II (BMI < 30) $(5.65 \pm 0.63$ versus $5.63 \pm 0.68)$ for Pre-operative End Systolic dimension; and (4.61 \pm 6.10 versus $3.72 \pm 0.60$ ) for Pre-operative End Diastolic dimension. In addition to that, group I $(\mathrm{BMI}>30)$ had higher mean Ejection Fraction (\%) rather than group II $(\mathrm{BMI}<30)(54.47 \pm 8.22$ versus $52.44 \pm 7.16)$.

There is a statistically insignificant difference between group I and group II as regards Coronary Angiography and Grafts ( $\mathrm{P}>0.05)$; however; group I had a higher prevalence of three-vessel disease rather than group II $(69.8 \%$ versus $53.3 \%)$ and had a higher prevalence of three Grafts rather than group II (62.3\% versus 53.3\%); as indicated in Table 4.

There is a statistically insignificant difference between group I and group II as regard Bypass time and Cross Clamp ( $>$ > 0.05); however; group I had higher mean Bypass time and Cross Clamp rather than group II (104.15 \pm 27.99 versus $99.44 \pm 30.44)$ for Bypass time; and $(72.36 \pm 20.95$ versus $67.91 \pm 16.76)$ for Cross Clamp (Operative details are shown in Table 5).

Table 6 shows a statistically insignificant difference between group I and group II as regard Inotropes and Intra-Aortic Balloon pump use $(\mathrm{P}>0.05)$; however; group I had a higher prevalence of more than two Inotropes used than group II ( $3.8 \%$ versus $0.0 \%)$; in addition to that; group I had lower prevalence of 
Table 4. Number of diseased vessels and final number of grafts.

\begin{tabular}{llcccccc}
\hline & & \multicolumn{2}{c}{ BMI $>30$} & \multicolumn{2}{c}{ BMI $<30$} & t-test & P-value \\
\hline Diseased vessels & Two vessel disease & 7 & $9.4 \%$ & 11 & $24.4 \%$ & & \\
& Three vessel disease & 37 & $69.8 \%$ & 24 & $53.3 \%$ & & \\
\multirow{4}{*}{ Grafts } & Four vessel disease & 9 & $17.0 \%$ & 10 & $20.0 \%$ & & \\
& One Graft & 3 & $5.7 \%$ & 1 & $2.2 \%$ & & \\
& Two grafts & 10 & $18.9 \%$ & 11 & $24.4 \%$ & 2.049 & 0.570 \\
& Three grafts & 33 & $62.3 \%$ & 24 & $53.3 \%$ & & \\
& Four grafts & 7 & $13.2 \%$ & 9 & $20.0 \%$ & & \\
\hline
\end{tabular}

Values are shown as mean $\pm \mathrm{SD}$, numbers and percentages as indicated, BMI Body Mass Index.

Table 5. Operative details.

\begin{tabular}{ccccccrr}
\hline \multirow{2}{*}{ Variables } & \multicolumn{5}{c}{ Patient Group } & & \\
\cline { 2 - 5 } & \multicolumn{2}{c}{ BMI $>30$} & \multicolumn{2}{c}{ BMI $<30$} & & Independent \\
sample t-test & P-value \\
\cline { 2 - 4 } & Mean & \pm SD & Mean & \pm SD & & \\
\hline Bypass time (Minutes) & 104.15 & 27.99 & 99.44 & 30.44 & 0.797 & 0.427 \\
Cross Clamp (Minutes) & 72.36 & 20.95 & 67.91 & 16.76 & 1.146 & 0.255 \\
\hline
\end{tabular}

Values are shown as mean \pm SD, BMI Body Mass Index.

Table 6. Need of Inotropes in the postoperative course.

\begin{tabular}{|c|c|c|c|c|c|c|c|}
\hline & \multirow{3}{*}{ Variables } & \multicolumn{4}{|c|}{ Patient Group } & \multirow{3}{*}{ Chi square test } & \multirow{3}{*}{$\mathrm{P}$-value } \\
\hline & & \multicolumn{2}{|c|}{$\mathrm{BMI}>30$} & \multicolumn{2}{|c|}{$\mathrm{BMI}<30$} & & \\
\hline & & No. & $\%$ & No. & $\%$ & & \\
\hline \multirow[t]{4}{*}{ Inotropes } & Not used & 13 & $24.5 \%$ & 13 & $28.9 \%$ & \multirow{4}{*}{1.729} & \multirow{4}{*}{0.704} \\
\hline & One Inotrope & 23 & $43.4 \%$ & 21 & $46.7 \%$ & & \\
\hline & Two Inotropes & 15 & $28.3 \%$ & 11 & $24.4 \%$ & & \\
\hline & More than two Inotropes & 2 & $3.8 \%$ & 0 & $0.0 \%$ & & \\
\hline \multirow[t]{2}{*}{ IABP } & Not used & 53 & $100.0 \%$ & 43 & $95.6 \%$ & \multirow{2}{*}{2.405} & \multirow{2}{*}{0.208} \\
\hline & Used & 0 & $0.0 \%$ & 2 & $4.4 \%$ & & \\
\hline
\end{tabular}

Values are shown as mean $\pm \mathrm{SD}$, numbers and percentages as indicated, BMI Body Mass Index, IABP Intra-Aortic Balloon Pump.

Intra-Aortic balloon use than group II ( $0.0 \%$ versus $4.4 \%)$.

While in Table 7, there is a statistically insignificant difference between group I and group II as regard ventilation time, ICU stay and Ejection Fraction (Postoperative) $(\mathrm{P}>0.05)$; where; group I had higher mean Ventilation time and ICU stay rather than group II $(8.71 \pm 6.14$ versus $8.40 \pm 6.49)$ and $(3.96 \pm 2.19$ versus $3.47 \pm 0.94$ ); on contrast; group I had lower mean Ejection Fraction (Postoperative) rather than group II ( $49.86 \pm 6.96$ versus $50.67 \pm 6.36)$.

There is a statistically significant difference between group I and group II as regard ward stay in days $(\mathrm{P}<0.05)$; where the group I had higher mean ward 
stay rather than group II (5.04 \pm 2.65 versus $4.09 \pm 1.33)$ (Table 7).

There is a statistically significant difference between group I and group II regarding incidence of wound infection $(\mathrm{P}<0.05)$; where the group I had a higher incidence of wound infection than group II (15.1\% versus $2.2 \%)$. There is a statistically significant difference between group I and group II as regard incidence of mediastinitis $(\mathrm{P}<0.05)$; group I had a higher incidence of mediastinitis than group II (9.8\% versus 2.2\%). Surprisingly; group I had a lower incidence of re-exploration than group II (2.0\% versus $4.4 \%)$; as shown in Table 8.

There is a statistically insignificant difference between group I and group II regarding in-hospital mortality $(\mathrm{P}>0.05)$; however; group I had higher hospital mortality than group II (3.8\% versus $0.0 \%)$.

There is a statistically insignificant difference between group I and group II regarding incidence of Chest infection and Cerebrovascular Stroke $(\mathrm{P}>0.05)$. However; group I had a lower incidence of Chest infection and Cerebrovascular Stroke than group II (9.8\% versus $11.1 \%)$ and (0.0\% versus $2.2 \%)$ respectively. In addition to that; none of the studied patients, in both groups had a liver impairment or renal impairment.

There is a statistically insignificant difference between group I (BMI > 30) and group II (BMI < 30) regarding wound-related sinus infection follow up (6 months) $(\mathrm{P}>0.05)$. However; group I (BMI > 30) had lower Sinus follow up (6 months) than group II (BMI < 30) $(9.4 \%$ versus $11.1 \%)$.

Table 7. Postoperative ICU and ward course.

\begin{tabular}{|c|c|c|c|c|c|c|}
\hline \multirow{3}{*}{ Variables } & \multicolumn{4}{|c|}{ Patient Group } & \multirow{3}{*}{$\begin{array}{l}\text { Independent } \\
\text { sample t-test }\end{array}$} & \multirow{3}{*}{ P-value } \\
\hline & \multicolumn{2}{|c|}{$\begin{array}{c}\text { Group I } \\
\text { BMI > } 30\end{array}$} & \multicolumn{2}{|c|}{$\begin{array}{l}\text { Group II } \\
\text { BMI }<30\end{array}$} & & \\
\hline & Mean & $\pm \mathrm{SD}$ & Mean & $\pm \mathrm{SD}$ & & \\
\hline Ventilation time (hours) & 8.71 & 6.14 & 8.40 & 6.49 & 0.237 & 0.813 \\
\hline ICU stay (days) & 3.96 & 2.19 & 3.47 & 0.94 & 1.402 & 0.164 \\
\hline Ejection Fraction (Postoperative) & 49.86 & 6.96 & 50.67 & 6.36 & -0.588 & 0.558 \\
\hline Ward stay (days) & 5.04 & 2.65 & 4.09 & 1.33 & 2.262 & $0.027^{\star}$ \\
\hline
\end{tabular}

Values are shown as mean \pm SD, BMI Body Mass Index, ${ }^{*}$ statistically significant value.

Table 8. Wound Infection in study cohort.

\begin{tabular}{|c|c|c|c|c|c|c|c|}
\hline \multirow{3}{*}{ Variables } & & \multicolumn{4}{|c|}{ Patient Group } & \multirow{3}{*}{ Chi square test } & \multirow{3}{*}{$\mathrm{P}$-value } \\
\hline & & \multicolumn{2}{|c|}{$\begin{array}{c}\text { Group I } \\
\text { BMI > } 30\end{array}$} & \multicolumn{2}{|c|}{$\begin{array}{c}\text { Group II } \\
\mathrm{BMI}<30\end{array}$} & & \\
\hline & & No. & $\%$ & No. & $\%$ & & \\
\hline \multirow{2}{*}{ Wound infection } & No & 45 & $84.9 \%$ & 44 & $97.8 \%$ & \multirow[b]{2}{*}{5.101} & \multirow[b]{2}{*}{$0.034^{\star}$} \\
\hline & Yes & 8 & $151 \%$ & 1 & $20 \%$ & & \\
\hline
\end{tabular}

Values are shown as numbers and percentages as indicated, BMI Body Mass Index, ${ }^{\star}$ statistically significant value. 


\section{Discussion}

Classification of overweight patients varies greatly between a BMI of 25 up to 40 . Being of a BMI of 25 - 29.9, i.e. below 30, makes the patient overweight but not obese. While a BMI 30 - 34.9 is a class 1 obesity, 35 - 39.9 is a class 2 and class 3 is equal or greater than 40 . Obesity is associated with many systemic comorbidities namely systemic hypertension, diabetes mellitus, dyslipidemia and cardiovascular diseases. All these comorbidities significantly increase the burden of undergoing CABG in such patients [7].

Many authors advocate obesity might not be a direct cause of mortality in cardiac patients undergoing CABG. However, when it comes to early morbidity following surgery and total hospital stay, obesity may be a game changer [8].

In our study, we found that there is no difference between group (I) and group (II) in age, sex and other co-morbidities like diabetes and hypertension. On the contrary to our findings, many other studies associate younger age with revascularization, denoting a higher risk among obese patients than in non-obese individuals. This is also true when it comes to comorbidities like hypertension and diabetes mellitus [7] [9].

Our study included predominantly obese male patients in contrast to other studies. Females in our cohort accounted for 39\% of our obese and 33\% of nonobese patients. This may be attributed to social and genetic properties in our community, Egyptian females tend to have late menopause, this means prolonged hormonal protection against coronary artery diseases. This natural physiologic protection is potentiated by less prevalence of smoking among females [10].

We found that the prevalence of diabetes is high in both groups and account for $56 \%$ of our obese and $46 \%$ of nonobese. Hyperglycemia is almost always identified as a risk factor for surgical site infection (SSI) [7].

This study demonstrated an increased risk of wound complications in obese patients. Group I (BMI > 30) suffered from wound infection and mediastinitis more than those in group II (BMI < 30) (15.7\% versus $2.2 \%)$ and $(9.8$ versus 2.2$)$ respectively. This finding conforms to that reported by Ridderstolpe and colleagues associating a high BMI $\left(>30 \mathrm{~kg} / \mathrm{m}^{2}\right)$ with a significant increase of risk of developing superficial and deep wound complications [10]. However, other studies found that there was no significant difference in wound infection rates that could be attributed to high BMI [7] [11].

Other post-operative morbidities e.g. chest infection, renal or hepatic affection along with new cerebrovascular strokes were not higher in obese patients. This is in concurrence with other studies [4] [8].

The study showed that the incidence of bleeding and reopening is higher in nonobese patients and other studies revealed the same result [2].

In our cohort, obese patients had a higher white blood cells count and more elevated serum cholesterol levels. This may be attributed to the link demonstrated by other studies between adipose tissue and obesity in one hand and in- 
duced inflammatory reactions with their adverse effects in the other hand [12].

The significant increase in total hospital, ward stays and rates of wound infection in obese patients in our study, conforms to many major studies [13]. By institutional policy, all patients with wound complications are to stay in-hospital till signs of bacteriological and clinical improvement appear. This explains the longer stay in group I.

The report of Kuduvalli and colleague may explain our finding of prolonged ventilation hours among obese patients (yet not significant in our study).He hypothesized that a relatively decreased vital lung capacity may play a role in respiratory functions impairment in obese patients. Also, a delayed slow release of anesthetic drugs stored in adipose tissues tends to have a depressive action on the respiratory drive [14] [15].

Statistically, there was an insignificant difference between group I (BMI $>30)$ and group II (BMI < 30) as regard Hospital Mortality $(\mathrm{P}>0.05)$; however; group I $($ BMI > 30) had higher Hospital Mortality rather than group II $(\mathrm{BMI}<30)$ $(3.8 \%$ versus $0.0 \%)$.The two cases of mortality were due to long bypass time and failure of weaning off the cardiopulmonary machine. This may be in line with authors reporting statistically insignificant differences in terms of mortality between obese and non-obese patients undergoing revascularization [2] [16].

Although development of medical care plans and marked improvement of health care services worldwide markedly reduced the impact of obesity on CABG patients; obesity still a major challenge [7]. The "less than optimum" surgical exposure of the field, the wide and deep field along with fatty lower limbs all add to the technical challenge. All these necessitate a gentle tissue handling, proper meticulous hemostasis and endoscopic graft harvesting during revascularization [17].

From our point of view, achieving a clean aseptic operative field is crucial in decreasing rates of wound-related complications. This can be achieved by simple measures like proper hemostasis, avoidance of too much debridement and excessive use of bone wax. This can also be potentiated by the application of vancomycin paste to sternal edges and bone marrow sinusoids. These measures, when combined with fast track anesthesia can help decrease ventilation time and subsequently ICU stay time. During ward stay aseptic, non-touch techniques during wound dressing can help to significantly decrease wound-related complications. Lastly, following culture sensitive antibiotics early in dealing with wound discharges can greatly affect the outcome and progression of the wounds [18].

\section{Limitations of the Study}

The study has its limitations of small number of patients with the exclusion of poorly controlled diabetic individuals, in whom diabetes may greatly affect the outcome of the study. Also, the study lacks follow up data for those patients to assess mid and late-term results and outcome. 


\section{Conclusion}

Obesity was associated with wound infection and mediastinitis more than non-obese patients. This led to prolonged ICU and in-hospital stay. Otherwise, it may not be associated with significant increase of mortality or other morbidities risks. Robust, specific antibiotic protocol must be started immediately post-operative to have an infection free wound.

\section{Conflicts of Interest}

The authors declare no conflicts of interest regarding the publication of this paper.

\section{References}

[1] Eagle, K.A., Guyton, R.A., Davidoff, R., Ewy, G.A., Fonger, J., Gardner, T.J., et al. (1999) ACC/AHA Guidelines for Coronary Artery Bypass Graft Surgery: Executive Summary and Recommendations. Circulation, 100, 1464-1480. https://doi.org/10.1161/01.CIR.100.13.1464

[2] Brandt, M., Harder, K., Walluscheck, K.P., Schottler, J., Rahimi, A., Moller, F., et al. (2001) Severe Obesity Does Not Adversely Affect Perioperative Mortality and Morbidity in Coronary Artery Bypass Surgery. European Journal of Cardio-Thoracic Surgery, 19, 662-666. https://doi.org/10.1016/S1010-7940(01)00647-9

[3] Engelman, D.T., Adams, D.H., Byrne, J.G., Aranki, S.F., Collins Jr., J.J., et al. (1999) Impact of Body Mass Index and Albumin on Morbidity and Mortality after Cardiac Surgery. The Journal of Thoracic and Cardiovascular Surgery, 118, 866-873. https://doi.org/10.1016/S0022-5223(99)70056-5

[4] Reeves, B.C., Ascione, R., Chamberlain, M.H. and Angelini, G.D. (2003) Effect of Body Mass Index on Early Outcomes in Patients Undergoing Coronary Artery Bypass Surgery. Journal of the American College of Cardiology, 42, 668-676. https://doi.org/10.1016/S0735-1097(03)00777-0

[5] Simopoulos, A.P. and Van Itallie, T.B. (1984) Body Weight, Health, and Longevity. Annals of Internal Medicine, 100, 285-295. https://doi.org/10.7326/0003-4819-100-2-285

[6] Ridderstolpe, L., Gill, H., Granfeldt, H., åhlfeldt, H. and Rutberg, H. (2001) Superficial and Deep Sternal Wound Complications: Incidence, Risk Factors and Mortality. European Journal of Cardio-Thoracic Surgery, 20, 1168-1175. https://doi.org/10.1016/S1010-7940(01)00991-5

[7] Ardeshiri, M., Faritous, Z., Haghighi, Z.O., Hosseini, S. and Baghaei, R. (2014) Effect of Obesity on Mortality and Morbidity after Coronary Artery Bypass Grafting Surgery in Iranian Patients. Anesthesiology and Pain Medicine, 4, e18884. https://doi.org/10.5812/aapm.18884

[8] Prabhakar, G., Haan, C.K., Peterson, E.D., Coombs, L.P., Cruzzavala, J.L. and Murray, G.F. (2002) The Risk of Moderate and Extreme Obesity for Coronary Artery Bypass Grafting Outcomes: A Study from the Society of Thoracic Surgeons' Database. The Annals of Thoracic Surgery, 74, 1125-1131. https://doi.org/10.1016/S0003-4975(02)03899-7

[9] Engel, A.M., McDonough, S. and Smith, J.M. (2009) Does an Obese Body Mass Index Affect Hospital Outcomes after Coronary Artery Bypass Graft Surgery? The Annals of Thoracic Surgery, 88, 1793-1800. 
https://doi.org/10.1016/j.athoracsur.2009.07.077

[10] Abdallah, A.G., Elnewihy, M.A., Brik, A.I. and Salem, A.M.M. (2017) Impact of Obesity on Early Cardiac Surgical Outcomes in Egypt: Early Outcomes of Coronary Artery Bypass Graft Surgery. Journal of the Egyptian Society of Cardio-Thoracic Surgery, 25, 192-197. https://doi.org/10.1016/j.jescts.2017.08.001

[11] Tokmakoglu, H. (2010) Operative and Early Results of Coronary Artery Bypass Grafting in Female Patients in Different Body Mass Indexes. Journal of Cardiothoracic Surgery, 5, 119. https://doi.org/10.1186/1749-8090-5-119

[12] Herishanu, Y., Rogowski, O., Polliack, A. and Marilus, R. (2006) Leukocytosis in Obese Individuals: Possible Link in Patients with Unexplained Persistent Neutrophilia. European Journal of Haematology, 76, 516-520. https://doi.org/10.1111/j.1600-0609.2006.00658.x

[13] Oreopoulos, A., Padwal, R., Norris, C.M., Mullen, J.C., Pretorius, V. and Kalantar-Zadeh, K. (2008) Effect of Obesity on Short- and Long-Term Mortality Postocoronary Revascularization: A Meta Analysis. Obesity, 16, 442-450. https://doi.org/10.1038/oby.2007.36

[14] Kuduvalli, M., Grayson, A.D., Oo, A.Y., Fabri, B.M. and Rashid, A. (2002) Risk of Morbidity and In-Hospital Mortality in Obese Patients Undergoing Coronary Artery Bypass Surgery. European Journal of Cardio-Thoracic Surgery, 22, 787-793. https://doi.org/10.1016/S1010-7940(02)00448-7

[15] Ray, C.S., Sue, D.Y., Bray, G., Hansen, J.E. and Wasserman, K. (1983) Effects of Obesity on Respiratory Function. American Review of Respiratory Disease, 128, 501-506. https://doi.org/10.1164/arrd.1983.128.3.501

[16] Wang, T.K.M., Ramanathan, T., Stewart, R., Gamble, G. and White, H. (2013) Lack of Relationship between Obesity and Mortality or Morbidity after Coronary Artery Bypass Grafting. The New Zealand Medical Journal, 126, 56-65.

[17] Yap, C.H., Zimmet, A., Mohajeri, M. and Yii, M. (2007) Effect of Obesity on Early Morbidity and Mortality Following Cardiac Surgery. Heart, Lung and Circulation, 16, 31-36. https://doi.org/10.1016/j.hlc.2006.09.007

[18] Abd Al Jawad, M.N. (2016) Proposed Model for Reducing Deep Sternal Wound Infection in Overweight Patients Undergoing Coronary Bypass Grafting: Strategies and Tricks. Ain Shams Medical Journal, 67, 511-518. 